\title{
Mammography Screening: Evidence, History and Current Practice in Germany and Other European Countries
}

\author{
Cornelis Biesheuvel $^{\mathrm{a}}$ Stefanie Weigel ${ }^{\mathrm{a}, \mathrm{b}} \quad$ Walter Heindel $\mathrm{l}^{\mathrm{a}, \mathrm{b}}$

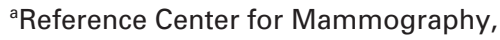 \\ ${ }^{b}$ Department of Clinical Radiology, University Hospital Muenster, Germany
}

Keywords

Breast cancer · Screening · Mammography

\section{Summary}

In this review, we describe the history, evidence, and current practice of mammography screening in Europe and the newly implemented screening program in Germany. We report results of the first screening rounds in North RhineWestphalia and compare these with reference values set by the European Guidelines for Quality Assurance in Breast Cancer Screening and Diagnosis. Finally, we summarize and compare performance indicators of the organized screening program in England, Italy, North Rhine-Westphalia and The Netherlands. Based on results of the first screening rounds, we conclude that the digital mammography screening program in North Rhine-Westphalia performs well and complies with the European guidelines. Besides relatively low attendance rates of approximately 53\%, implementation of the German organized breast cancer screening program was successful.

\section{Introduction}

The primary aim of the German mammography screening program, which was rolled out in 2005 and adheres to the European Guidelines for Quality Assurance in Breast Cancer Screening and Diagnosis [1], is to reduce breast cancer mortality by early detection of breast cancer in asymptomatic women. In this review, we will first shortly describe the history, evidence, and current practice in mammography screening in Europe in general. Secondly, we focus on the newly implemented mammography screening program in Germany. Thirdly, we will report performance indicators of the first screening rounds of the program in Germany's most populous state, North Rhine-Westphalia (NRW), and compare these with reference values set by the European

\author{
Schlüsselwörter \\ Brustkrebs · Screening · Mammographie
}

\section{Zusammenfassung}

Diese Übersichtsarbeit beleuchtet die Entwicklung und Evidenz des Mammographie-Screenings in Europa und das neu implementierte Screening-Programm in Deutschland. Die Ergebnisse der ersten Screening-Runden in NordrheinWestfalen werden mit den von den Europäischen Leitlinien zur Qualitätssicherung im Mammographie-Screening und bei der Diagnose vorgegebenen Referenzwerten verglichen. Zudem werden die Leistungsindikatoren der organisierten Screening-Programme in England, Italien, Nordrhein-Westfalen und den Niederlanden kritisch gegenübergestellt. Die Ergebnisse der ersten Screening-Runden in Deutschland belegen, dass das digitale Mammographie-ScreeningProgramm gut etabliert werden konnte und in Einklang mit den Europäischen Richtlinien steht. Abgesehen von der noch relativ geringen Teilnehmerrate von $53 \%$ ist das organisierte Brustkrebs-Screening-Programm in Deutschland erfolgreich gestartet.

guidelines [1]. Finally, we compare screening performance indicators of the mammography screening programs in England, Italy, The Netherlands, and NRW.

\section{Evidence, History, and Current State of Mammography Screening in Europe}

When launching the 'Europe against Cancer' program in 1986, the Committee of Cancer Experts of the European Community (EC) decided that systematic population-based screening should be implemented for those cancers for which such strategy had been shown to reduce mortality. Nowadays, the Council of Europe recommends population-based organized mammography screening for breast cancer for women

\section{KARGER}

Fax +497614520714

Information@Karger.de

www.karger.com (c) 2011 S. Karger GmbH, Freiburg

$1661-3791 / 11 / 0062-0104 \$ 38.00 / 0$

Accessible online at:

www.karger.com/brc
Dr. Cornelis Biesheuvel, Epidemiologist

Reference Center for Mammography at the University Hospital Muenster

Albert-Schweitzer-Str. 33, 48149 Münster, Germany

Tel. +49 251 834-7215, Fax -5660

biesheuvel@referenzzentrum-ms.de 
aged 50-69 years and requires that screening programs comply with the European guidelines $[1,2]$.

The effectiveness of mammography screening has been evaluated in randomized controlled trials. These have consistently shown mortality reductions of $20-35 \%$ amongst women in the age range of 50-69 years [3-5]. Following the early results of these trials, the EC proposed pilot screening programs to its member states in 1986. Several countries including Sweden, the UK and The Netherlands had already decided to implement a nationwide mammography screening program. Pilot screening programs were established in Belgium, Denmark, France, Greece, Ireland, Luxemburg, Portugal, and Spain. To stimulate dissemination of screening expertise among member states, the EC established the European pilot screening network. At the request of the Subcommittee on Screening of the 'Europe against Cancer' program, experts participating in this network developed the first edition of the European guidelines on population-based service screening for breast cancer [6]. The current 4th edition of these guidelines was published in 2006 [1].

Over 254 million women are currently living in one of the 27 member states of the European Union (EU); approximately 60 million of them are aged between 50 and 69 years. Screening programs incorporating assurance mechanisms for both radiology and pathology services are running or being

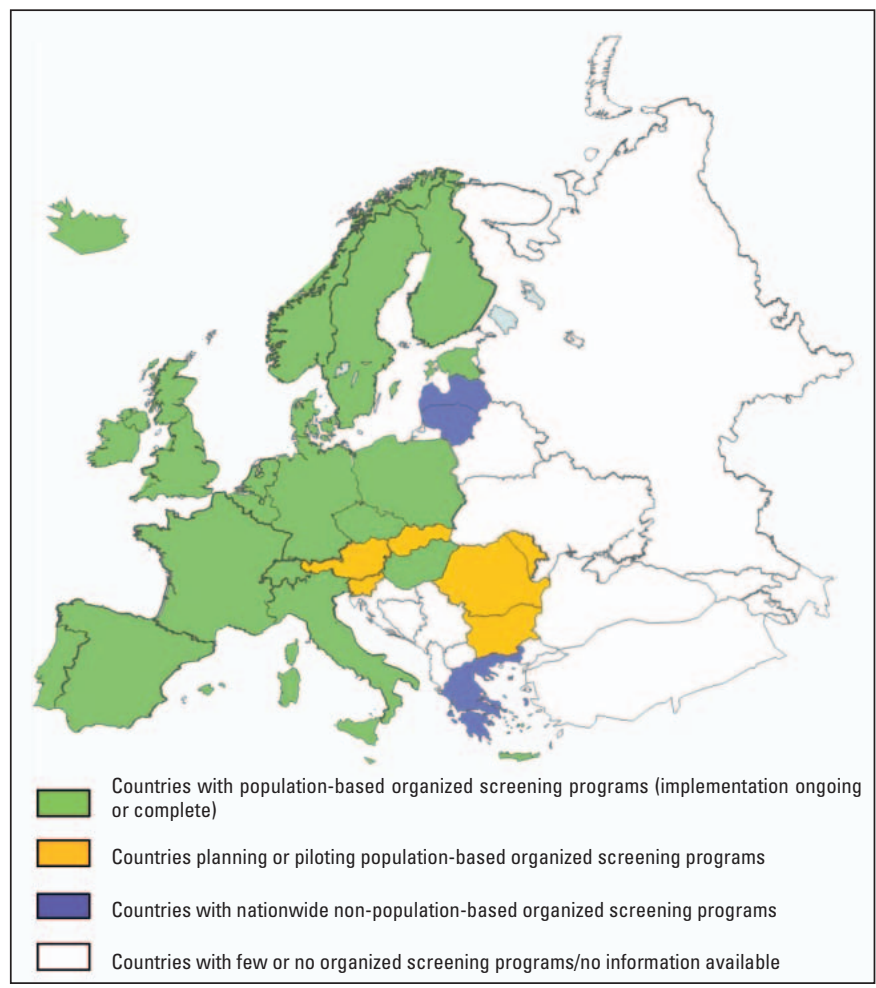

Fig. 1. Breast screening program in Europe by program type (population-based; non-population-based; no program) and implementation status (ongoing or complete; planning or piloting). Both Austria and Latvia plan transition from the currently implemented non-populationbased programs to population-based screening. Sources: European Cancer Observatory [8] and Organization for Economic Co-operation and Development [21]. established in 26 of the 27 member states (fig. 1) [7, 8]. Most programs target women in the age group of 50-69 years, with a 2-year interval between screening tests. Other European countries with long-established organized mammography screening programs are Norway, Iceland, and the Frenchspeaking cantons of Switzerland.

Meanwhile, several comprehensive evaluations of the population-based screening programs have been conducted. For example, in The Netherlands, a statistically significant reduction in breast cancer mortality of $19.9 \%$ among women aged 55-74 years was reported 11 years after introduction of mammography screening, as compared with the period before the introduction of screening [9]. An evaluation of mammography screening in 13 Swedish areas found a $43 \%$ reduction in breast cancer mortality associated with being screened, after adjustment for self-selection for screening, and a $27 \%$ reduction associated with the policy of offering screening $[10,11]$. In Denmark, a significant $25 \%$ reduction in breast cancer mortality was shown within 10 years after the introduction of screening in Copenhagen, compared with rates before screening commenced and control areas without screening [12].

The magnitude of mammography screening effectiveness has been questioned lately in analyses of the Norwegian and Danish screening program $[13,14]$. This dissent can be explained by both the difficulties of separating the intertwining effects of early detection by screening and improvements in therapy on breast cancer mortality reduction over time and the many factors that may distort estimates of screening effectiveness when analyzing observational data from screening programs compared to those from randomized controlled trials. However, almost all experts, including so-called screening skeptics, agree that there is sufficient evidence to assume that mammography screening reduces breast cancer mortality. The actual magnitude of this reduction and the impact of negative screening effects (false-positive and false-negative results and overtreatment of small cancers) is still a hotly debated topic.

\section{History and Current State of Mammography Screening in Germany}

In 2002, the German parliament decided to introduce a nationwide breast screening program for women aged 50-69 years that adheres to the European guidelines. For this purpose, the statutory health insurance schemes (Krankenkasse), together with the federation of health insurance scheme doctors (Kassenärztliche Vereinigung), founded the national Mammography Cooperative. Five national reference centers are tasked with quality assurance and monitoring of the screening program, each supervising a number of screening units operating in their region. The screening units are specialized diagnostic imaging centers, certified to execute the mammography screening program according to the European 
Table 1. Performance indicators of the mammography screening program in North Rhine-Westphalia from 2005 to 2009

\begin{tabular}{|c|c|c|c|c|c|c|}
\hline & $\begin{array}{l}\text { EU guidelines [1]: } \\
\text { acceptable level; } \\
\text { desirable level }\end{array}$ & 2005-2006 & 2007 & 2008 & 2009 & $2005-2009$ \\
\hline Number of invitations & & 196,182 & 706,169 & $1,007,849$ & $1,122,238$ & $3,032,438$ \\
\hline Attendance rate, $\%$ & $>70 ;>75$ & 59.0 & 52.0 & 52.8 & 54.1 & 53.4 \\
\hline $\begin{array}{l}\text { Recall rate, } \% \\
\text { Initial screening examination } \\
\text { Subsequent screening examination }\end{array}$ & $\begin{array}{l}<7 ;<5 \\
<5 ;<3\end{array}$ & $\begin{array}{l}5.9 \\
-\end{array}$ & $\begin{array}{l}5.4 \\
-\end{array}$ & $\begin{array}{l}5.8 \\
3.3\end{array}$ & $\begin{array}{l}7.4 \\
3.4\end{array}$ & $\begin{array}{l}6.1 \\
3.4\end{array}$ \\
\hline $\begin{array}{l}\text { Breast cancer detection rate } \\
\text { (per } 1000 \text { participants) } \\
\text { Initial screening examination } \\
\text { Subsequent screening examination }\end{array}$ & $\begin{array}{l}3 \times \mathrm{IR} ;>3 \times \mathrm{IR} \\
1.5 \times \mathrm{IR} ;>1.5 \times \mathrm{IR}\end{array}$ & $\begin{array}{l}3.2 \times \operatorname{IR}(8.4) \\
-\end{array}$ & $\begin{array}{l}2.9 \times \operatorname{IR}(7.6) \\
-\end{array}$ & $\begin{array}{l}3.2 \times \operatorname{IR}(8.4) \\
2.3 \times \operatorname{IR}(0.61)\end{array}$ & $\begin{array}{l}3.2 \times \operatorname{IR}(0.82) \\
2.3 \times \operatorname{IR}(0.59)\end{array}$ & $\begin{array}{l}3.1 \times \operatorname{IR}(0.81) \\
2.3 \times \operatorname{IR}(0.60)\end{array}$ \\
\hline Proportion DCIS, \% & $10 ; 10-20$ & 21.2 & 18.7 & 18.9 & 19.4 & 19.1 \\
\hline $\begin{array}{l}\text { Proportion invasive cancers } \leq 10 \mathrm{~mm}, \% \\
\text { Initial screening examination } \\
\text { Subsequent screening examination }\end{array}$ & $\begin{array}{l}\text { n.a.; } \geq 25 \\
\geq 25 ; \geq 30\end{array}$ & $\begin{array}{l}26.7 \\
-\end{array}$ & $\begin{array}{l}29.5 \\
-\end{array}$ & $\begin{array}{l}27.7 \\
40.5\end{array}$ & $\begin{array}{l}31.0 \\
34.1\end{array}$ & $\begin{array}{l}29.1 \\
35.0\end{array}$ \\
\hline $\begin{array}{l}\text { Proportion of cancers UICC II+, \% } \\
\text { Initial screening examination } \\
\text { Subsequent screening examination }\end{array}$ & $\begin{array}{l}<30 \\
25 ;<25\end{array}$ & $\begin{array}{l}29.9 \\
-\end{array}$ & $\begin{array}{l}29.4 \\
-\end{array}$ & $\begin{array}{l}29.5 \\
19.5\end{array}$ & $\begin{array}{l}30.4 \\
24.9\end{array}$ & $\begin{array}{l}30.0 \\
23.4\end{array}$ \\
\hline
\end{tabular}

IR = Breast cancer incidence rate among women aged 50-69 years in the years preceding screening (2.6 per 1000), DCIS = ductal carcinoma in situ, UICC $=$ International Union against Cancer, n.a. = not applicable.

guidelines. All parties involved in the German mammography screening program must adhere to strict federal and state laws on personal data protection.

Prior to the nationwide implementation of the populationbased German mammography screening program, its feasibility was examined by 3 pilot projects in the cities of Bremen and Wiesbaden and the rural area Weser-Ems, over the years 2001-2005 [15]. Based on the outcomes and knowledge gained by these projects, roll-out of the nationwide screening program started in 2005 and was completed by 2009. So far, over $90 \%$ of all eligible women have been invited for screening.

Invitation units (Zentralstellen) invite women in the age range of 50-69 years to participate in the screening program at 2-year intervals by sending a personal invitation letter with a fixed appointment which can be changed on request. Nonresponders receive a reminder in about 6 weeks after they miss the initial appointment. For the purpose of the mammography screening program, invitation units receive limited personal data on eligible women from local or regional population registers. These data must be deleted shortly after (re) invitations have been sent.

All mammograms are read independently by 2 specialized breast radiologists at the screening units. To resolve discrepancies between the interpretations of the 2 readers, review by consensus including a 3 rd reader is mandatory. All women are personally informed by letter about the outcome of the screening examination. Assessment of screen-detected breast lesions is organized at screening unit level. The results of the initial screening round, conducted from 2005 to 2007, are reported in the 'Evaluationsbericht 2005-2007' [16].

\section{Results of the Mammography Screening Program in North Rhine-Westphalia}

In this section, we will first describe the implementation of the mammography screening program in North Rhine-Westphalia. Secondly, we compare important performance indicators with reference values set by the European guidelines.

North Rhine-Westphalia is Germany's most populous state, with approximately 18 million inhabitants and 2.2 million women of screening age, thereby constituting just over $1 / 5$ of the screening target population of Germany. In the years directly preceding the onset of population-based mammography screening, breast cancer incidence and mortality were 2.6 and 0.70 , respectively, per 1000 women aged 50-69 years. Organized mammography screening started in 2005, and since then the Reference Center for Mammography at the University Hospital of Münster has been responsible for the ongoing monitoring of the breast screening program. State-wide coverage was reached in August 2008 when the 23rd screening unit started. In the first 3 years, all but one screening unit used digital techniques. By the end of 2008, this screening unit also changed to digital screening.

From 2005 until 2009, a total of 3,032,438 screening invitations were sent out. Invitation rates increased from $17.6 \%$ in 2005 to over $100 \%$ in 2009 to compensate for the limited capacity in the previous years (table 1). A total of 1,589,015 women attended screening, yielding an overall attendance rate of $53.4 \%$. Of all screens, $79.8 \%$ were initial ones and $20.2 \%$ were subsequent examinations. The recall rate for further assessment of screen-detected abnormalities was $6.1 \%$ for initial screens and $3.4 \%$ for subsequent screens. The cor- 
responding average breast cancer detection rates for initial and subsequent screening examinations were 3.1 and 2.3 times the background incidence of $0.26 \%$, respectively. The proportion of all screen-detected cancers that were ductal carcinoma in situ (DCIS) was $19.1 \%$. The proportions of screen-detected invasive cancers $\leq 10 \mathrm{~mm}$ were $29.1 \%$ and $35.0 \%$ for initial and subsequent screening examinations, respectively. Of all invasive cancers, $75.4 \%$ and $79.5 \%$ were node negative for initial and subsequent screening examinations, respectively; $30.0 \%$ (initial screen) and $23.4 \%$ (subsequent screen) of invasive cancers were in stage II+ (UICC). Almost all screening performance indicators were in compliance with the EU guidelines.

T-stage distributions of invasive breast cancers diagnosed in the years preceding the introduction of the mammography screening program in the Muensterland region (2002-2004) and all cancers detected by the screening program in North Rhine-Westphalia (including the Muensterland region) from 2005 to 2009 are shown in figure 2. Invasive breast cancers detected within the screening program showed a more favorable distribution towards small sizes (T1mic, T1ab) than those detected before the program commenced.

\section{Screening Performance Indicators of 4 European Mammography Screening Programs}

In both England and The Netherlands, population-based organized screening programs started about 20 years ago. In 2001, the upper age limit for screening was extended to 70 years in England; until then the upper age limit was 64 . The screening interval remained at 36 months. In The Netherlands, the upper age limit for screening was extended from 69 to 75 years after implementation of the screening program was completed in 1997. The mammography screening program in Italy started in 2002. Large differences in screening implementation and quality are reported among the northern and southern regions. Like in Germany, women aged 50-69 years are invited at 24-month intervals. Further characteristics of the 4 screening programs are shown in table 2.

In table 3 , we show recent data on invitation, attendance, and selected screening performance indicators for the different mammography screening programs. Attendance rates were highest in The Netherlands: $79.0 \%$ for initial and $82.8 \%$ for subsequent screens. Recall rates for initial and subsequent screening examinations were lowest in The Netherlands, whereas cancer detection rates were relatively high (5.9 and 5.2 per 1000 participants, respectively). For the other programs, recall rates on initial screens exceeded the target levels set by the EU guidelines. However, in both England and North Rhine-Westphalia, cancer detection rates were higher than those in The Netherlands. We also note that observed differences between countries should be interpreted with caution as many factors may be responsible for this. For example, both breast cancer risk differences among women attending the program and the average length of the screening interval vary among countries.

\section{Discussion}

We described evidence, implementation, and current practice of mammography screening in Europe and, more specifically, Germany. Our analysis of the first screening rounds conducted from 2005 to 2009 in North Rhine-Westphalia indicates that the organized mammography screening program performs well and complies with the EU guidelines. In accordance with previous analyses [17], breast cancers were detected in earlier

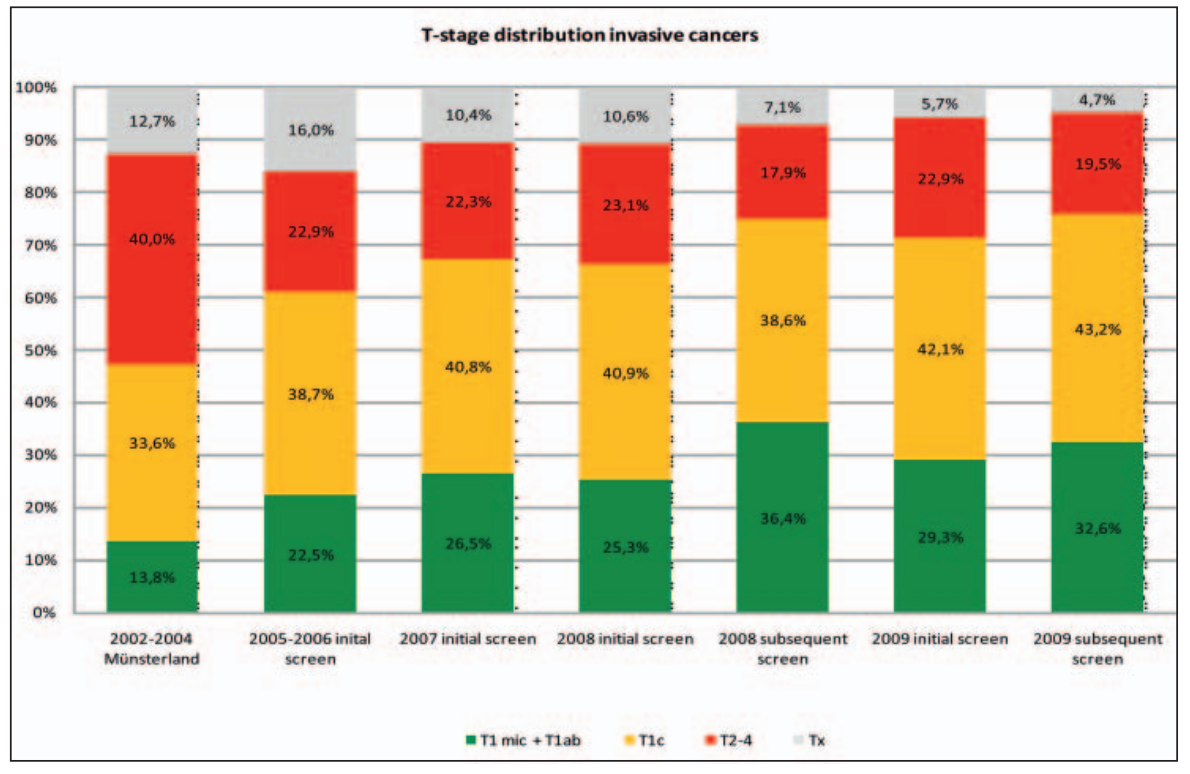

Fig. 2. T-stage distribution of symptomatic invasive breast cancers diagnosed in the Muensterland region from 2002 to 2004 (before implementation of the mammography screening program) and invasive breast cancers detected within the mammography screening program in North Rhine-Westphalia, including the Muensterland region, from 2005 to 2009. Data source T-stage distribution invasive cancers 2002-2004: Epidemiological Cancer Registry North Rhine-Westphalia (EKRNRW). 
Table 2. Characteristics of the national mammography screening programs in Italy, North Rhine-Westphalia (Germany), The Netherlands and England

\begin{tabular}{|c|c|c|c|c|c|c|}
\hline Country, region, state & $\begin{array}{l}\text { Year } \\
\text { program } \\
\text { started }\end{array}$ & $\begin{array}{l}\text { Year complete coverage } \\
\text { was achieved }\end{array}$ & $\begin{array}{l}\text { Implementation of } \\
\text { digital techniques? }\end{array}$ & $\begin{array}{l}\text { Screening } \\
\text { age range, } \\
\text { years }\end{array}$ & $\begin{array}{l}\text { Screening } \\
\text { interval, } \\
\text { months }\end{array}$ & $\begin{array}{l}\text { Approximate number } \\
\text { of women in the } \\
\text { screening target } \\
\text { population in } 2007\end{array}$ \\
\hline England & 1988 & $\begin{array}{l}\text { approximately } 75 \% \text { of } \\
\text { the screening target } \\
\text { population was invited } \\
\text { by the end of } 2009\end{array}$ & $\begin{array}{l}\text { implementation of } \\
\text { digital screening from } \\
2005 \text {, not completed yet }\end{array}$ & $50-70^{\mathrm{a}}$ & 36 & 6.0 million \\
\hline Italy & 2002 & $\begin{array}{l}\text { over } 90 \% \text { of the } \\
\text { screening target } \\
\text { population was invited } \\
\text { by the end of } 2007\end{array}$ & no data available & $50-69$ & 24 & 3.2 million \\
\hline $\begin{array}{l}\text { North Rhine-Westphalia } \\
\text { (Germany) }\end{array}$ & 2005 & 2009 & from 2009 , fully digital & $50-69$ & 24 & 2.2 million \\
\hline The Netherlands & 1990 & 1997 & from 2010 , fully digital & $50-75^{\mathrm{b}}$ & 24 & 2.2 million \\
\hline
\end{tabular}

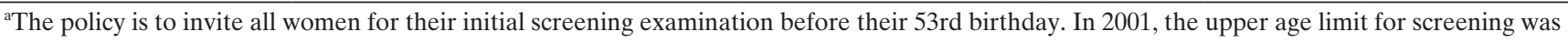
extended to 70 years; until then the upper age limit was 64 years.

bIn 1998, the upper age limit for screening was extended to 75 years; until then the upper age limit was 69 years.

Table 3. Current performance indicators of the population-based mammography screening programs in England (50-70 years), Italy (50-69 years), North Rhine-Westphalia (50-69 years) and The Netherlands (50-75 years)

\begin{tabular}{|c|c|c|c|c|c|c|c|c|}
\hline $\begin{array}{l}\text { Country, region, } \\
\text { state }\end{array}$ & Data source & $\begin{array}{l}\text { Data are } \\
\text { reported } \\
\text { for the } \\
\text { year(s) }\end{array}$ & $\begin{array}{l}\text { Number } \\
\text { of invited } \\
\text { women } \\
\text { (million) }\end{array}$ & $\begin{array}{l}\text { Screening } \\
\text { examination }\end{array}$ & $\begin{array}{l}\text { Attendance } \\
\text { rate, \% }\end{array}$ & $\begin{array}{l}\text { Recall } \\
\text { rate, \% }\end{array}$ & $\begin{array}{l}\text { Cancer } \\
\text { detection } \\
\text { rate (per } \\
1000 \\
\text { women } \\
\text { screened) }{ }^{\mathrm{a}} \\
\end{array}$ & $\begin{array}{l}\text { Proportion of } \\
\text { invasive cancers } \\
<10 \mathrm{~mm} \text { (of all } \\
\text { screen-detected } \\
\text { invasive cancers, } \\
\%)^{\mathrm{b}}\end{array}$ \\
\hline \multirow{2}{*}{ England } & \multirow[t]{2}{*}{ National Health Service [22] } & \multirow[t]{2}{*}{$2008-2009$} & \multirow[t]{2}{*}{2.2} & initial & 69.0 & 8.6 & 7.3 & 25.9 \\
\hline & & & & subsequent $^{\mathrm{c}}$ & 87.4 & 3.2 & 7.4 & 26.9 \\
\hline \multirow[t]{2}{*}{ Italy } & The National Center for & \multirow[t]{2}{*}{2007} & \multirow[t]{2}{*}{2.2} & initial & $61.0^{\mathrm{d}}$ & 9.4 & 5.4 & 363 \\
\hline & $\begin{array}{l}\text { Screening Monitoring } \\
\text { (Osservatorio Nazionale } \\
\text { Screening) [23] }\end{array}$ & & & subsequent & & 4.1 & 4.8 & 303 \\
\hline \multirow{2}{*}{$\begin{array}{l}\text { North Rhine-West- } \\
\text { phalia (Germany) }\end{array}$} & Reference Center for & \multirow[t]{2}{*}{2009} & \multirow[t]{2}{*}{1.1} & \multirow{3}{*}{$\begin{array}{l}\text { initial } \\
\text { subsequent } \\
\text { initial } \\
\text { subsequent }\end{array}$} & $54.1^{\mathrm{d}}$ & 7.4 & 8.2 & 31.0 \\
\hline & Mammography Muenster & & & & & 3.4 & 5.9 & 34.1 \\
\hline The Netherlands & The National Evaluation & 2007 & 1.1 & & 79.0 & 3.5 & 5.9 & 284 \\
\hline
\end{tabular}

${ }^{a}$ Estimated from reported overall cancer detection rate, detection rate of invasive cancers $\leq 10 \mathrm{~mm}$ and rate of DCIS.

${ }^{b}$ Estimated from reported T1a + T1b rate, T1c rate and T2 rate among women aged 50-69 years, not separated by screening examination.

${ }^{c}$ Routine invitation $<5$ years after last screening examination among women who previously attended mammography screening.

${ }^{\mathrm{d}}$ Average attendance in both initial and subsequent screening examinations.

stages of disease than before implementation of the program and, although recall rates exceeded desirable levels, the corresponding breast cancer detection rates were relatively high, considering the historical setting of widespread opportunistic screening. We believe that these promising results capture the benefits of digital screening and, more specifically, the improved detection of calcification-related malignancies [18].

Despite all public relations efforts, attendance rates were relatively low (approximately 53\%). This may be partly explained by continuation of breast screening activities outside the organized program (so-called opportunistic or gray screening), especially among women with private health insurance. Before implementation of the screening program, it was estimated that $25 \%$ of all women aged $40-70$ years had screening mammograms at regular intervals [19]. Another factor may be the ongoing public discussion about benefits and harms of screening. Based on the observed high proportion of screen-detected small invasive cancers and other beneficial findings, we expect a growing acceptance of the organized mammography screening program in Germany.

Besides a potential reduction of breast cancer mortality of up to $30 \%$ among screening participants, other major benefits of the organized screening program are a reduction in the need for extensive (neoadjuvant) therapy, implementation of specialized multidisciplinary breast centers in which dedicated health care professionals work together to improve overall breast cancer care for all, and the increase of breast health awareness among women of all ages. Among the negative 
effects of mammography screening are exposure to radiation, the diagnosis of cancers that would never have led to symptomatic disease if left undetected (overdiagnosis) with consequential overtreatment, distress among women who are recalled for further assessment of screen-detected lesions that prove to be benign (false-positive results), and existing malign lesions not detected by screening (false-negative results). To facilitate informed individual decision making by women of screening age, the Mammography Cooperative has published an evidence-based fact sheet including a flow chart with estimates of benefits and risks accumulated over 20 years of biannual mammography screening [20]. In this fact sheet, it is estimated that 200 women need to be screened for 20 years (10 screening examinations) to prevent 1 breast cancer death. Further, it is estimated that of these 200 women, 1 extra woman will be diagnosed with breast cancer compared to a non-screening control population, and 50 women will be recalled for the assessment of a benign lesion.

Additional future analyses of the German mammography screening program should focus on interval breast cancers. The German cancer registries are tasked with the identification of interval cancers by comparing encrypted data on attendance and screening results from the screening and invitation units with all breast cancer cases reported from hospitals and pathologists. This enables identification of interval cancers and cancers detected among non-responders. We also aim to conduct a comprehensive cost-benefit analysis, including the effect of the mammography screening program on breast cancer mortality.

In conclusion, by analyzing the first rounds of the newly implemented mammography screening program in North Rhine-Westphalia, we showed that the German program performed well and complies with the European guidelines. The joint efforts of all personnel responsible for execution of the program, the comprehensive quality assurance measures, and the predominant use of digital techniques resulted in successful implementation and good performance of the population-based mammography screening program in Germany.

\section{Disclosure Statement}

The authors have no conflict of interest.

\section{Acknowledgement}

The authors kindly thank the clinical directors (Programmverantwortliche Ärzte) of all 23 screening units of North Rhine-Westphalia for screening-related data collection and transfer of screening performance indicators to the Reference Center for Mammography in Muenster.

\section{References}

1 Perry N, Broeders M, de Wolf C, Törnberg S, Holland R, von Karsa L: European Guidelines for Quality Assurance in Breast Cancer Screening and Diagnosis. Luxembourg, Office for Official Publications of the European Communities, 2006.

2 Communities CotE: Council Recommendation on Cancer Screening 20033.

3 Tabar L, Vitak B, Chen HH, Duffy SW, Yen MF, Chiang CF, Krusemo UB, Tot T, Smith RA: The Swedish Two-County Trial twenty years later. Updated mortality results and new insights from long-term follow-up. Radiol Clin North Am 2000; 38:625-651.

4 Nystrom L, Andersson I, Bjurstam N, Frisell J, Nordenskjold B, Rutqvist LE: Long-term effects of mammography screening: updated overview of the Swedish randomised trials. Lancet 2002;359:909919.

5 Bjurstam N, Bjorneld L, Warwick J, Sala E, Duffy SW, Nystrom L, Walker N, Cahlin E, Eriksson O, Hafstrom LO, Lingaas H, Mattsson J, Persson S, Rudenstam CM, Salander H, Save-Soderbergh J, Wahlin T: The Gothenburg Breast Screening Trial. Cancer 2003;97:2387-2396.

6 Kirkpatrick A, Törnberg S, Thijssen M: European guidelines for quality assurance in mammography screening. Luxembourg, European Commission, 1993.

7 von Karsa L, Anttila A, Ronco G, Ponti A, Malila $\mathrm{N}$, Arbyn M, Segnan N, Castillo-Beltran M, Boniol M, Ferlay J, Hery C, Sauvaget L, Voti P, Autier P: Cancer Screening in the European Union; Report on the Implementation of the Council Recommendation on Cancer Screening. Luxembourg, European Commission, 2008.
8 ECO, European Cancer Observatory, International Agency for Research on Cancer, http://eu-cancer. iarc. fr , accessed on 12/01/2011.

9 Otto SJ, Fracheboud J, Looman CW, Broeders MJ, Boer R, Hendriks JH, Verbeek AL, de Koning HJ: Initiation of population-based mammography screening in Dutch municipalities and effect on breast-cancer mortality: a systematic review. Lancet 2003;361:1411-1417.

10 Tabar L, Yen MF, Vitak B, Chen HH, Smith RA, Duffy SW: Mammography service screening and mortality in breast cancer patients: 20 -year followup before and after introduction of screening. Lancet 2003;361:1405-1410.

11 Swedish Organised Service Screening Evaluation Group (SOSEG): Reduction in breast cancer mortality from organized service screening with mammography: 1 . Further confirmation with extended data. Cancer Epidemiol Biomarkers Prev 2006; 15:45-51.

12 Olsen AH, Njor SH, Vejborg I, Schwartz W, Dalgaard P, Jensen MB, Tange UB, Blichert-Toft M, Rank F, Mouridsen H, Lynge E: Breast cancer mortality in Copenhagen after introduction of mammography screening: cohort study. BMJ 2005;330:220.

13 Kalager M, Zelen M, Langmark F, Adami HO: Effect of screening mammography on breastcancer mortality in Norway. N Engl J Med 2010; 363:1203-1210.

14 Jorgensen KJ, Zahl PH, Gotzsche PC: Breast cancer mortality in organised mammography screening in Denmark: comparative study. BMJ 2010;340:c1241.
15 Kääb R, Wulf $\mathrm{T}$, Becker N, Borowski M: Mammographie-Screening in Deutschland: $\mathrm{Ab}$ schlussbericht der Modellprojekte Köln, Mammography cooperative, 2006.

16 Malek D, Rabe P: Evaluationsbericht 2005-2007; Ergebnisse des Mammographie-Screening-Programms in Deutschland. Berlin. Mammography cooperative, 2009

17 Weigel S, Batzler WU, Decker T, Hense HW, Heindel W: First epidemiological analysis of breast cancer incidence and tumor characteristics after implementation of population-based digital mammography screening. Rofo 2009;181:1144-1150.

18 Weigel S, Decker T, Korsching E, Hungermann D, Bocker W, Heindel W: Calcifications in digital mammographic screening: improvement of early detection of invasive breast cancers? Radiology 2010;255:738-745.

19 Gibis B, Busse R, Reese K, Richter K, Schwartz FW, Köbberling J: Das Mammographie-Screening als Verfahren zur Brustkrebsfrüherkennung. BadenBaden, Nomos Verlag, 1998.

20 Weymayr C: Kennzahlen Mammographie-Screening. Berlin, Kooperationsgemeinschaft Mammographie, 2010.

21 www.ecosante.org/OCDEENG/311010.html, accessed on 12.01.2011.

22 National Health Service: Breast Screening Programme, England 2008-2009. UK, NHS, 2010.

23 Giordano L, Giorgi D, Piccini P, Ventura L, Stefanini V, Senore C, Castagn R, Paci E, Segnan $\mathrm{N}$ : Time trends of process and impact indicators in Italian breast screening programmes: 1998-2007. Epidemiol Prev 2009;33(suppl 2):29-39.

24 National Evaluation of Breast Cancer Screening in The Netherlands. Rotterdam, NETB, 2009. 